\title{
Functional Morphology and Behavior of Early Life Stages of Red Sea Bream
}

\author{
Osamu FuKuHARA* \\ (Accepted October 15, 1984)
}

\begin{abstract}
Larval red sea bream were reared in the laboratory to describe the development of organs and behavior, and their implications on early life stage. Transformation from post-larval to juvenile stages occurred when fish attained $7.6 \mathrm{~mm} \mathrm{SL}$ to $8.6 \mathrm{~mm} \mathrm{SL} ; 25$ to 29 days after they were hatched. During this phase, organogenesis occurred internally, and subsequent developmental stages were observed externally.

With the functional development of the various organs, fish behaviors particularly swimming speed, increased remarkably. In the wild, change in fish habits was also found as the individuals developed.

Consequently, it is considered that the morphological development and organogenesis were closely implicated with the change in the life style of the red sea bream.
\end{abstract}

Red sea bream Pagrus major is the most important species to commercial fisheries in marine coastal waters in Japan. Recently artificial propagation for intensive farming and for stocking recruits has been performed vigorously, thus promoting coastal fisheries. Considering the increasing importance of the species to fisheries, more biological information on the early life history is needed. Little literature, however, exists on the functional morphology and behavior of the larval and juvenile stages. Most research on external morphology has focused on eggs and larval development. ${ }^{1-s}$ ) Some internal morphological aspects have been studied such as the development of the digestive tract, ${ }^{(0)}$ skeletal structures, $^{7,8)}$ muscles $^{9)}$ and other interior organs. ${ }^{10,11)}$

Concerned with functional aspects of organogeneis, $O^{\prime}$ CONNELI ${ }^{12)}$ recently reviewed the development of internal organ systems and their ecological implication on marine fish larvae.

The object of this study is to clarify the relationship between morphological development and differentiation and development of fish behaviors as they relate to the life mode of early life stages of red sea bream.

\section{Materials and Methods}

Rearing Techniques

Viable eggs spawned from parental fish main- tained in captivity were collected with a fine-mesh net. Newly hatched larvae were maintained in a $1000 l$ or $500 l$ capacity tanks at densities of 20,000 to 30,000 larvae $/ \mathrm{m}^{3}$.

Cultured rotifer Brachionus plicatilis were used as initial food organisms; later larvae were reared on the diet of copepods (Tigriopus japonicus) or Artemia nauplii and minced fish and mollusk meat (Table 1). A non-flowing water system was used for the first 25 to 30 days of the rearing period, after which a running water system was used. The rearing conditions of temperature, salinity and feeding schedules are summarized in Table 1.

\section{Preservation}

Five percent non-buffered seawater formalin (29-32 S\%o) was used to preserved specimens less than about $8.0 \mathrm{~mm} \mathrm{SL}$, whereas $10 \%$ formalin solution was used for longer fish. No correction factor was employed to adjust size changes due to shrinking caused by formalin.

\section{Observations and Measurements}

Preserved fish specimens were used for morphological and meristic observations on external and internal organs. Alizarin Red $\mathbf{S}$ and Rose Bengal staining were employed for inspecting fin development, squamation and intestinal development, respectively under dissecting and/or hugepower microscope.

Body dimension of smaller fish were recorded

* Nansei Regional Fisheries Research Laboratory, Ohno, Saeki, Hiroshima 739-04, Japan (福原 修: 南西 海区水産研究所). 
Table 1. Summary of rearing conditions for Pagrus major during 1975 to 1983

\begin{tabular}{|c|c|c|c|c|c|c|c|}
\hline \multirow{2}{*}{ Year } & \multirow{2}{*}{ Duration } & \multirow{2}{*}{ W.T. $\left({ }^{\circ} \mathrm{C}\right)$} & \multirow{2}{*}{$\mathrm{S} \%$} & \multicolumn{4}{|c|}{ Food organisms fed } \\
\hline & & & & Rotifer & Copepods & Artemia & Minced meat \\
\hline 1975 & June $7-J u l .16$ & $\begin{array}{c}19.2-24.8^{* 1} \\
22.8\end{array}$ & . & $5-8^{* 2}$ & $10-30$ & $20-38$ & $35-$ \\
\hline 1977 & May 30-Sept. 27 & $\begin{array}{c}19.4-26.7 \\
23.7\end{array}$ & $\begin{array}{c}29.4-30.8 \\
30.1\end{array}$ & $3-20$ & $18-35$ & & $26-$ \\
\hline 1978 & May 27-July. 6 & $\begin{array}{c}18.6-24.2 \\
21.6 \\
\end{array}$ & & $3-20$ & $17-32$ & & $23-$ \\
\hline 1979 & May 20-Jul. 10 & $15.4-24.9$ & & $2-18$ & & & \\
\hline 1981 & Jun. 17-Aug. 14 & $\begin{array}{c}18.2-25.7 \\
23.3 \\
\end{array}$ & $\begin{array}{c}27.4-31.5 \\
30.1 \\
\end{array}$ & $3-27$ & & $20-27$ & $27-$ \\
\hline 1982 & May 13-Jun. 14 & $\begin{array}{c}16.4-23.0 \\
19.7 \\
\end{array}$ & $\begin{array}{c}30.4-32.0 \\
31.6 \\
\end{array}$ & $2-30$ & & & \\
\hline 1983 & May 23-Jun. 28 & $\begin{array}{c}19.1-21.5 \\
20.4\end{array}$ & & $2-25$ & & $18-37$ & \\
\hline
\end{tabular}

aided by a profile projector with an electric microscope at a precision of $0.001 \mathrm{~mm}$. Larger fish were measured by calipers with an accuracy of $0.5 \mathrm{~mm}$. The body dimensions measured were preanal length (PL) from tip of the snout to the anus; standard length (SL) from tip of the snout to the end of the notochord for the larval stage, and to the base of the caudal fin for metamorphosed specimens: and total length (TL) from the tip of the snout to the posterior margin of the caudal an.

\section{Results}

Eggs

Fertilized eggs were spherical in shape, averaging $0.918 \pm 0.029 \mathrm{~mm}$ in diameter (mean $\pm \mathrm{SD}, \mathrm{n}=$ 103). Perivitelline space was narrow and contained a single oil globule. Cultured parent produced various sized eggs spontaneously, which ranged from $0.66 \mathrm{~mm}$ to $1.03 \mathrm{~mm}(\mathrm{n}=4,986)$ in diameter. The eggs hatched after $48-50 \mathrm{~h}$ at about $20^{\circ} \mathrm{C}$.

\section{Development of Larvae and Juveniles}

Newly hatched larvae measured $2.01 \pm 0.06 \mathrm{~mm}$ $\mathrm{TL}$ and $1.93 \pm 0.06 \mathrm{~mm}$ SL (mean $\pm \mathrm{SD}, \mathbf{n}=55$ ). A large yolk sac was present with a single oil globule, located posteriorly. At about $20^{\circ} \mathrm{C}$ the mouth was opened on day 2 after hatching, and the yolk was absorbed at 3 days. No marked changes were noted until the larvae attained $5.6 \mathrm{~mm} \mathrm{SL}$ (Fig. 1A).
Larvae of $5.6 \mathrm{~mm}$ in length (SL), with notochord flection, had fan-shaped pectoral fins without rays; the base of the dorsal and anal fins first appeared; and the caudal fin was rounded. The end of maxillary was positioned beneath the middle of the orbit.

When larvae attained $6.5 \mathrm{~mm}$ SL (Fig. 1B) the unpaired fins developed, and the soft-rays of the pectoral fins, and the buds of the ventral fins appeared. At a length of $7.6 \mathrm{~mm} \mathrm{SL}$ all the fins had formed completely. The melanophores were concentrated at the spinous portion of the dorsal fin and in the cephalic area, and the caudal fin was truncated (Fig. 1C). Melanophores increased along the dorsal surface and also vertically of the posterior ends of the dorsal and anals fins (Fig. 1D). Melanophores became more prominent along the lateral surface of body as they grew, and the caudal fin emarginated (Fig. 1E, F).

Pigmentation intensified shortly after fish reached the juvenile (Fig. 1 G-I). The outer soft rays of the ventral fins elongated, characteristics of larger individuals; pigmentation along the lateral surface revealed five vertical bands that were more clear than before, and the lateral line was easily distinguishable (Fig. 1J, K).

Ossification of the caudal region began at $5.6 \mathrm{~mm}$ SL (Fig. 1A). At this size, the hypural bones were developing and some rays were observed in the ventral half of the caudal fin-fold. At a length of about $8.0 \mathrm{~mm} \mathrm{SL}$, vertebral column was easily recongizable, and the pectoral girdles were starting to appear. Ossification of the dorsal and 


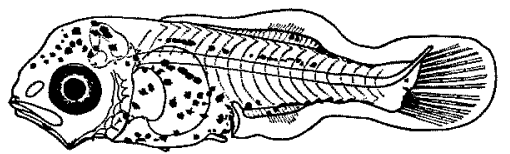

A

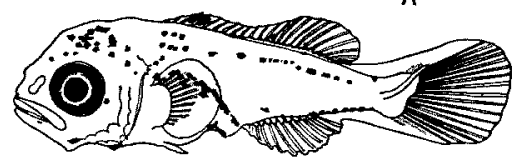

$\mathbf{B}$

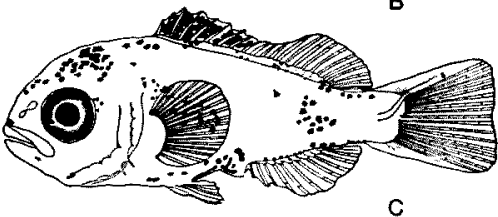

C
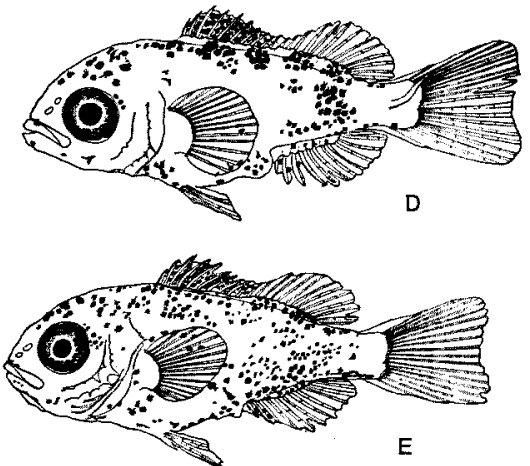

E

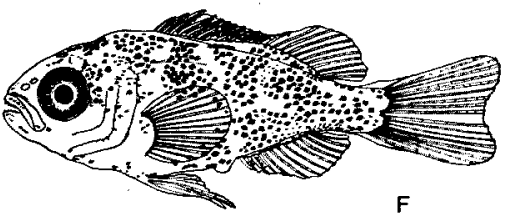

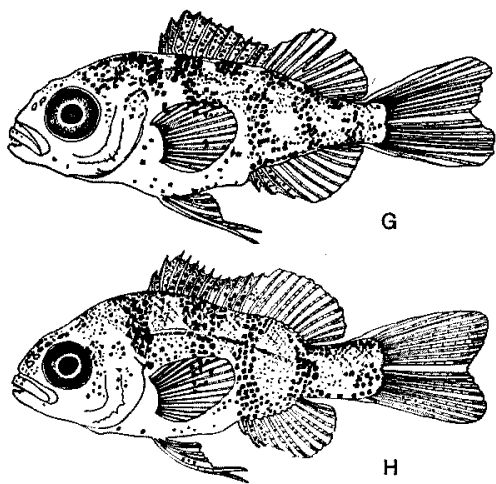
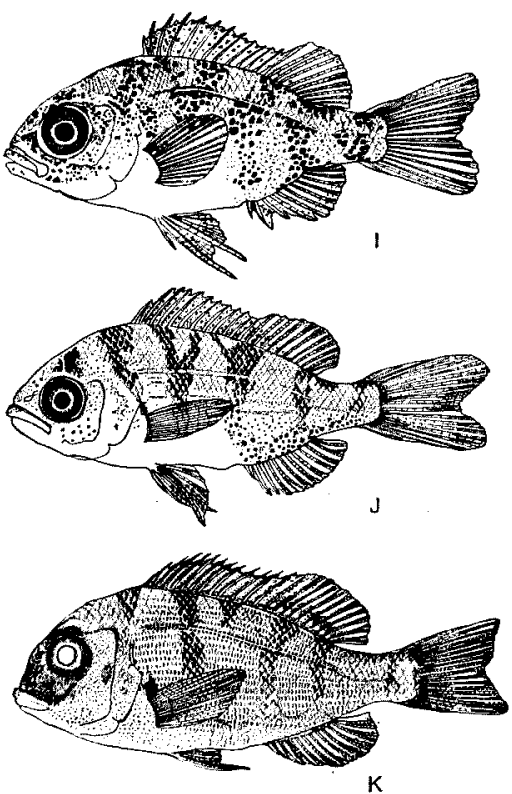

Fig. 1. Developmental stages of Pagrus major reared in the laboratory. ${ }^{13)}$ A, 5.6 mmSL; B, $6.5 \mathrm{mmSL} ; \mathrm{C}, 7.6 \mathrm{mmSL} ; \mathrm{D}, 8.3 \mathrm{mmSL}$; E, $8.9 \mathrm{mmSL}$; F, $10.2 \mathrm{mmSL}$; G, $11.8 \mathrm{mmSL}$; H, 14.1 mmSL; I, $19.1 \mathrm{mmSL}$; J, 30.8 mmSL; K, $46.1 \mathrm{mmSL}$.

anal fin pterygiophores began at about $10.0 \mathrm{~mm}$ SL, and well-developed pterygiophores could be distinguished on $30.0 \mathrm{~mm}$ SL specimens.

\section{Fin Development}

The sequence of developmental changes in the fin-fold of larval fish is presented graphically in Fig. 2. The primordial fin-fold of newly hatched larvae was present until the notochord became flexible, and the base of the dorsal and anal fins appeared (Fig. 1A, Fig. 2A, B). At this stage the fin-fold, located just anterior of the anus was visible. Unpaired fin began to develop on speci- mens 6.0 to $6.5 \mathrm{~mm} \mathrm{SL}$ with a change in marginal shape of the fin-fold (Fig. 1B, Fig. 2C). The shape of the caudal fin was closely related with fin and larval development (Fig. 3), The posterior margin of the caudal fin was rounded until the larvae attained about $8.0 \mathrm{~mm}$ SL. A truncatedshaped caudal fin was observed for a short period during the transformation to early juveniles, ranging from 6.3 to $10.3 \mathrm{~mm}$ SL (Fig. 1C, Fig. 2D, E). Therefore, the truncated caudal fin was indicative of changing the developmental stages from post-larvae to juvenile. Dorsal, anal and caudal fins were separated completely at the 

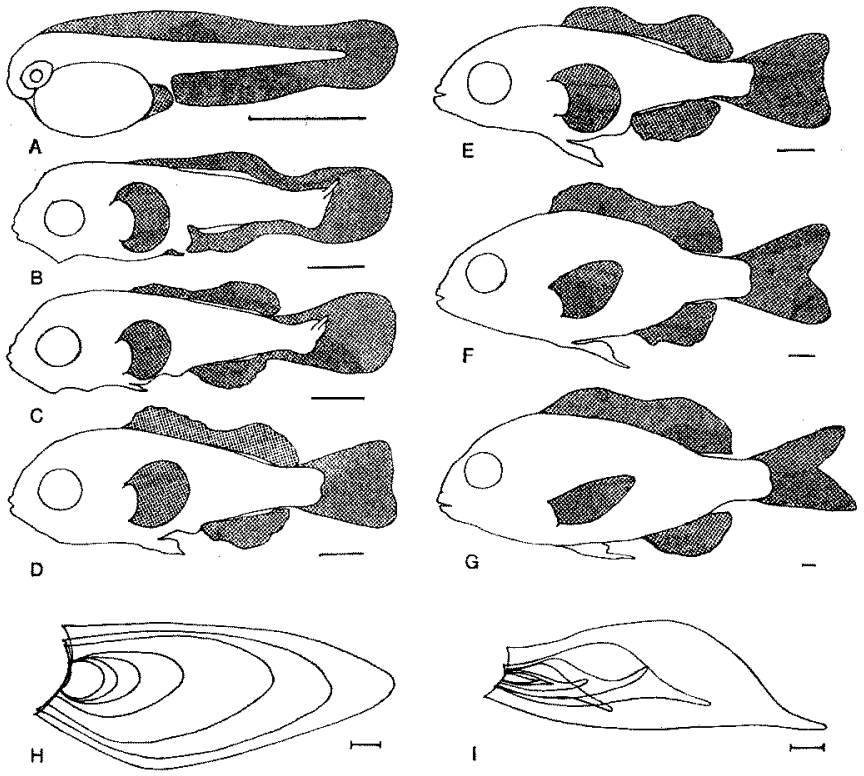

Fig. 2. Semidiagrams showing developmental change in unpaired (A-G) and paired (H, I) fins ${ }^{14}$ ): A, pre-larva; B, C, post-larva; D, transitional phase; E, F. Juvenile; G, young; H, pectoral fin; $\mathrm{I}$, ventral fin. Scales denote $1.0 \mathrm{~mm}$.

caudal peduncle when larvae reached the early juvenile stage, $7.6 \mathrm{~mm}$ to $8.6 \mathrm{~mm}$ SL.

All juveniles ranging from 8.5 to $20.8 \mathrm{~mm} \mathrm{SL}$ had emarginated shaped caudal fin (Fig. 1E-I, Fig. 2F). Adult form of a furcated caudal fin was found on specimens larger than $18.0 \mathrm{~mm} \mathrm{SL}$ (Fig. 1J, K, Fig. 2G).

The pectoral and ventral fins became pointed and elongated when the developing fish transformed from early juvenile to juvenile or young stages (Fig. 1C-J). The shape of pectoral fins tends to be long and pointed for these fast swimming fishes. Probably aiding in swimming ability. Increments in lengths of the pectoral and ventral fins were expressed by equations of $Y=0.232 X-$ 0.182 ( $n=233, r=0.993, Y$; SL, $X$; length of the ventral fins) and $Y=0.267 X-0.489 \quad(n=102$, $r=0.936, Y$; SL, $X$; length of the ventral fins) for specimens ranged from $2.0 \mathrm{~mm}$ to $50 \mathrm{~mm}$ SL.

A full complement of fin rays occurred at 7.6 $\mathrm{mm}$ SL for the smallest specimen, and at $8.6 \mathrm{~mm}$ SL for the largest one, thus the transformation from the larval to juvenile stage occurred when fish were $7.6 \mathrm{~mm}$ to $8.6 \mathrm{~mm} \mathrm{SL}$ as mentioned before.

Rayed fins developed in the following sequence: caudal, anal, dorsal, ventrals and pectorals. After a full complement of softrays had developed in each fin, segmentation of rays began, earlier in unpaired fins than in paired fins (Fig. 3, 4).

Caudal fin rays began to segment at about 6.0 $\mathrm{mm} \mathrm{SL}$, anal fin rays at $6.2 \mathrm{~mm}$ SL, dorsal fin ray at $6.4 \mathrm{~mm} \mathrm{SL}$, ventral fins at $7.0 \mathrm{~mm}$ SL and pectoral fins at $7.6 \mathrm{~mm}$ SL. The fin rays were fully segmented at $7.8,8.2,7.5,10.3,18.0 \mathrm{~mm} \mathrm{SL}$, respectively.

Branching of soft rays began after segmentation was completed, except for the ventral fins (Fig. 4). Soft ray branching began at approximately $11.0 \mathrm{~mm}$ SL for the anal, and $12.0 \mathrm{~mm} \mathrm{SL}$ for the caudal and dorsal fins, $8.0 \mathrm{~mm}$ SL for the ventral fins and $11.0 \mathrm{~mm} \mathrm{SL}$ for the pectoral fins. Branching was completed at $20.5 \mathrm{~mm}$ SL for the caudal, $23.3 \mathrm{~mm}$ SL for the anal and $26.5 \mathrm{~mm} \mathrm{SL}$ for the dorsal, $15.6 \mathrm{~mm} \mathrm{SL}$ for the ventrals and $34.0 \mathrm{~mm}$ SL for the pectorals, respectively.

Consequently all fin rays were completely segmented by $18.0 \mathrm{~mm} \mathrm{SL}$, and were branched when fish were $34.0 \mathrm{~mm} \mathrm{SL}$. The flexibility of a fin ray is presumably related with segmentation as described by GosLiNe. ${ }^{18)}$

\section{Pigmentation and Pigment Pattern}

Newly hatched larvae have melanophores around the cephalic region, on the oil globule located posteriorly in the yolk sac, and scantily along the trunk and caudal region. By day 3 , 

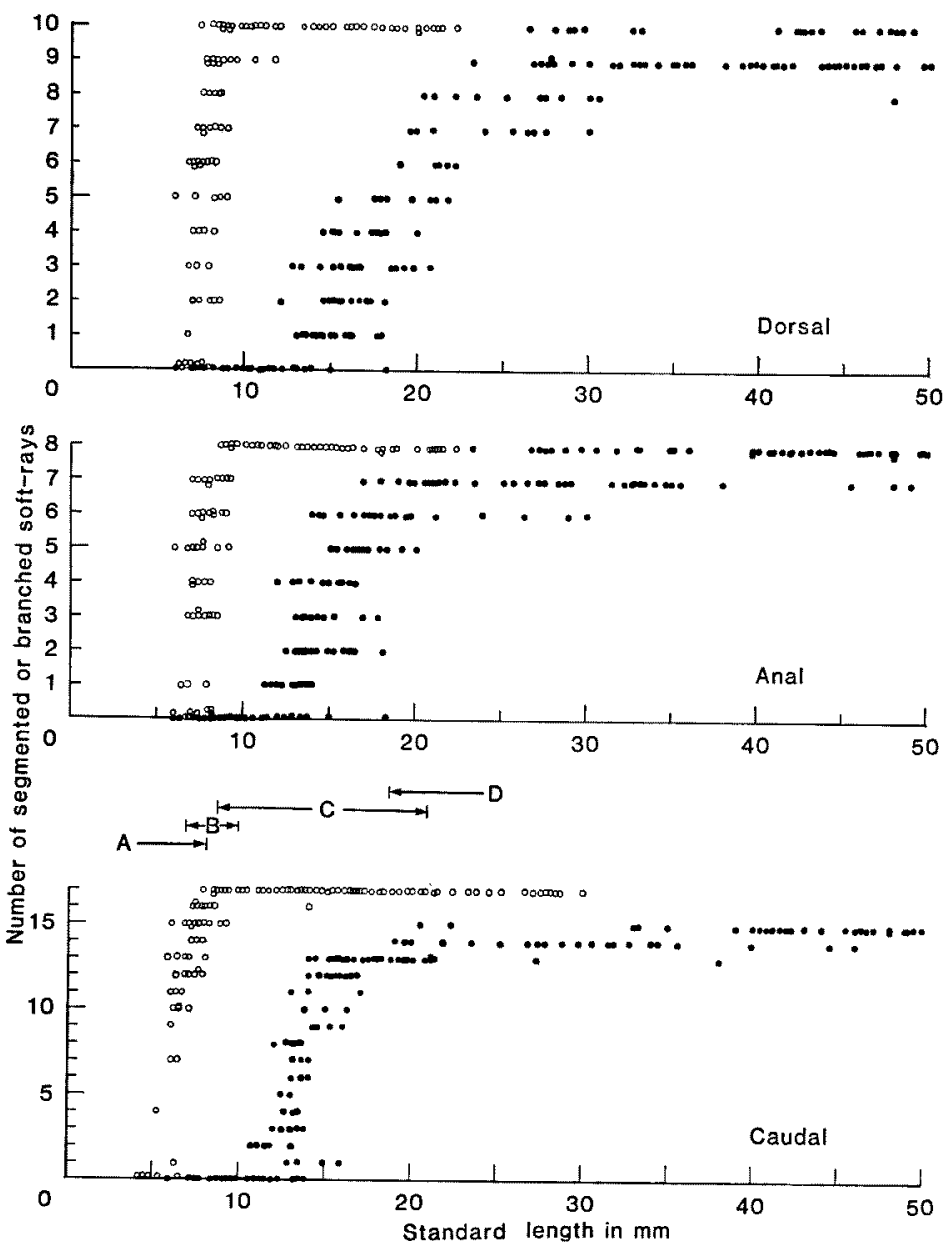

Fig. 3. Segmentation (open circles) and branching (closed circles) of soft-rays in the unpaired fins. ${ }^{14)}$ A-D indicate the shape of caudal fin; A, rounded; B, truncated; C, emarginated; $D$, furcated.

melanophores appeared on the snout and on the gut. Small melanophores were also serially arranged along the ventral midline between the anus and caudal fin. During the larval stage no marked change in pigment occurred (Fig. 1A, B). In the early juvenile stage, the spinous portion of the dorsal fin became pigmented more intensively, and the number of melanophores increased in the cephalic region (Fig. 1C). Relatively larger melanophores, which composed a pigment band in subsequent development, was distributed vertically below the dorsal and at the posterior portion of the anal fin (Fig. 1D).

The formation of pigment pattern is shown in
Fig. 5. Each stage is identified by the appearance of the pigment pattern and the number of transverse bands on the lateral surface. Fig. 6 shows the relation between developmental stage, larval size and ages. The pigment pattern first appeared in larvae about $7.5 \mathrm{~mm}$ SL when the melanophores concentrated around the posterior end of the dorsal fin (Fig. 5B, Fig. 6). Three pigment patches occurred on the nape and the base of the spinous dorsal fin. The pigment pattern formed at the posterior end of the dorsal fin and extended toward the ventral surface (Fig. 5C). In larvae measuring $8.0 \mathrm{~mm}$ SL, the pigment pattern occurring anterior of the caudal peduncle covered 


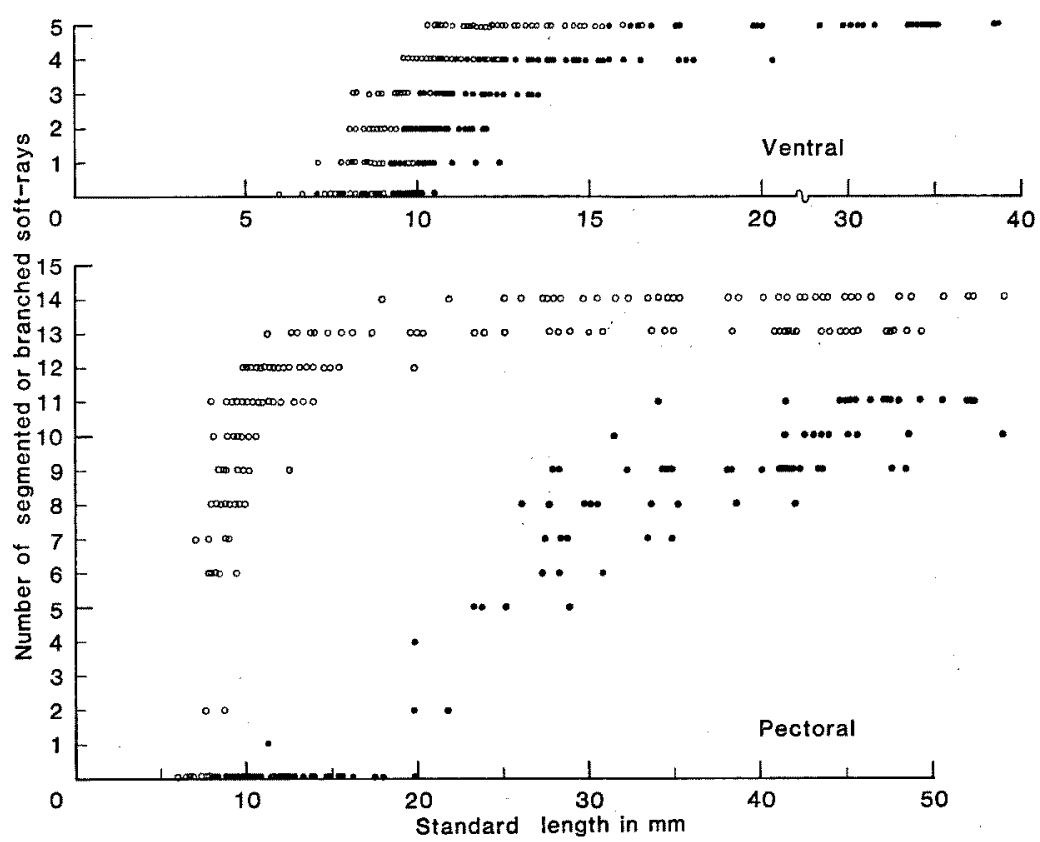

Fig. 4. Segmentation (open circles) and branching (closed circles) of soft rays in the paired fins.

the entire depth of the trunk (Fig. 5D). A separate, elongated patch of melanophores developed at the base of the soft dorsal fin, and the two became connected by a narrow bridge of melanophores when the larvae attained a length of about $\mathbf{8 . 0}$ mm SL (Fig. 5E). The pigment pattern was connected at the anal fin base, was elongated posteriorly, and was connected with a small patch located on the caudal peduncle (Fig. 5G). The smallest fish with a completely formed pigment band was $9.0 \mathrm{~mm} \mathrm{SL}$, and Fig. 6 indicates that all specimens larger than $11.0 \mathrm{~mm}$ SL had clearly completed the formation of five distinct stripes. The commencement of band formation occurred on larvae on day 27; all larvae had completely formed bands after 41 days.

\section{Squamation}

Squamation in developing larvae may be divided into 8 steps (Fig. 7). Each stage was assigned by two basic criteria: the number of rows of scales, and the extent of body coverage. Fig. 8 shows the developmental stages plotted against standard length.

Scales first arised along the lateral line at the posterior end of the trunk (Fig. 7A). The largest specimen without scales was about $9.0 \mathrm{~mm}$ SL, and the smallest with scales was $7.5 \mathrm{~mm}$ SL (Fig.
8). The subsequent development of the scale pattern occurred more rapidly anteriorly and posteriorly, and less rapidily dorsally and ventrally (Fig. 7B-D). In stage D larvae, the squamated area extended posterior of the operculum, and anterior of the caudal peduncle. With increased larval growth, the squamated area extended in all directions (Fig. 7E). Only the nape, thoracic, and base of the unpaired fins were devoid of scales (Fig. 7F), and the unscaled areas narrowed as development proceeded (Fig. 7G). The first fish that was completely scaled (Fig. $7 \mathbf{H}$ ) was about $10.0 \mathrm{~mm}$ SL and the largest fish not completely scaled was about $13.0 \mathrm{~mm}$ long. All fish over $14.0 \mathrm{~mm}$ SL were fully squamated (Fig. 8).

\section{Development of Digestive Organ}

The sequence of development in the digestive organs during the larvae to juvenile stage is shown in Fig. 9. The digestive tract during larval phase was convolved (Fig. 9A) until larvae attained 7.5 $\mathrm{mm} \mathrm{SL}$ as indicated in Fig. 10. The pyloric caeca appeared, and posterior portion of the digestive tract was curved slightly (Fig. 9B) when larvae reached the size of $5.5 \mathrm{~mm}$ to $9.1 \mathrm{~mm} \mathrm{SL}$, corresponding to the transformation from the larval stage to the juvenile stage. The specimens over $10 \mathrm{~mm}$ SL had well-developed pyloric caeca, and 


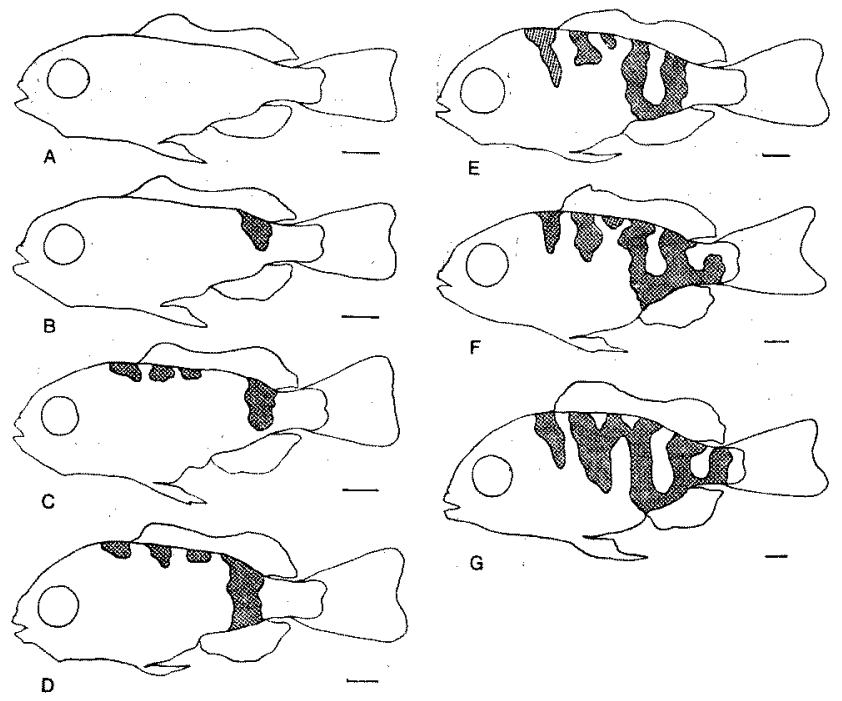

Fig. 5. Semidiagrammatic drawing of sequence in pigment pattern distinguished by the number of transverse bands formed on the body surface. ${ }^{15)}$ Scales denote $1.0 \mathrm{~mm}$.

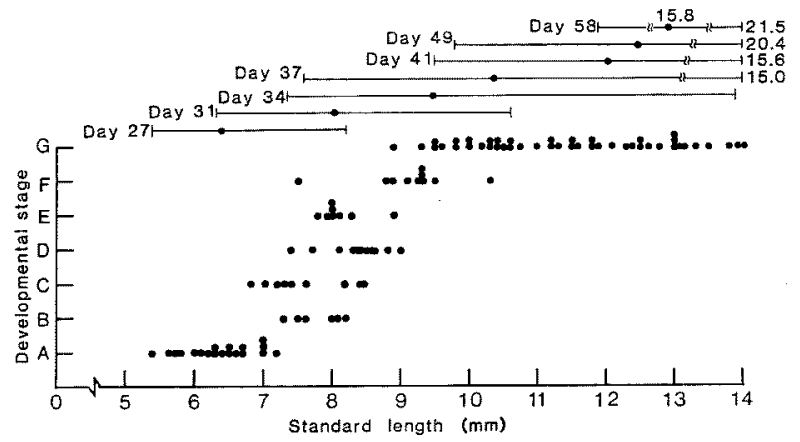

Fig. 6. Development of pigment pattern plotted against standard length. Stages A-G identical to the descriptions in Fig. 5. Minimum, mean and maximum size of each sampling day are also indicated.

the digestive tract angled posteriorly, just in front of rectum (Fig. 9C). As development proceeded, pyloric caeca elongated and the shape of digestive tract became deeply rounded and curved (Fig. 9D).

\section{Behaviors}

Because the larvae were buoyant due to their yolk sacs, they were concentrated in the surface layer of the tank and were at the mercy of water movement caused by aeration.

Spontaneous movement and/or swimming behaviour were observed after yolk was absorbed. About one day after yolk absorption, fed larvae started to move actively during a one-minute observation period. Conversely, movements of unfed larvae declined (Fig. 11).

Swimming speed increments are provided in Fig. 12. Swimming speed, which was measured both before and after feeding, was less than $50 \mathrm{~cm} /$ min; 1SL/s during larval phase. It subsequently increased to more than $100 \mathrm{~cm} / \mathrm{min} ; 3 \mathrm{SL} / \mathrm{s}$. during the transitional phase from post-larvae to juvenile. Concurrent rises in swimming speeds of about $200 \mathrm{~cm} / \mathrm{min}$., corresponding to $4 \mathrm{SL} /$ s., were noted for the metamorphosed fish. Fast swimming was observed in low prey density than 

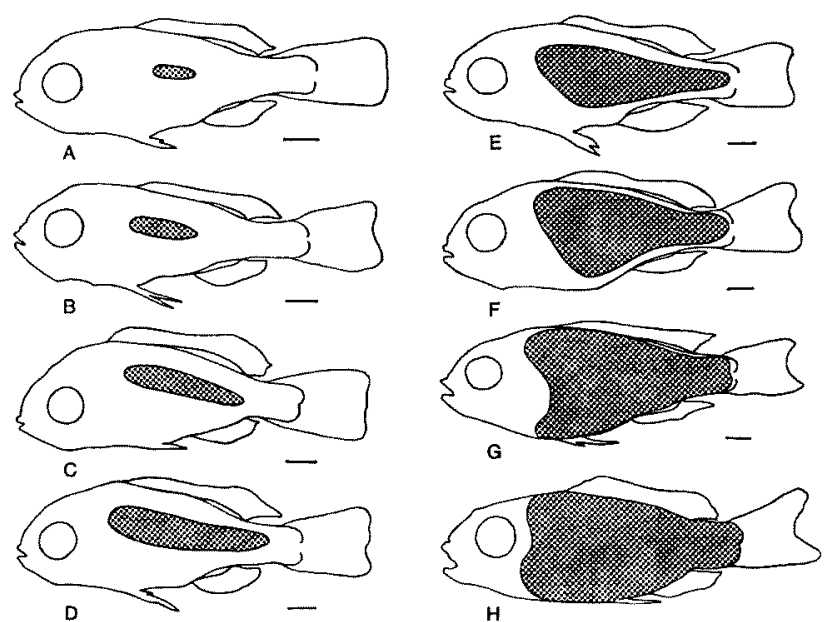

Fig. 7. Diagrammatic illustrations of squamation. ${ }^{18)}$ A-H are the arbitrary defined stages of development; see text for details. Scales denote $1.0 \mathrm{~mm}$.

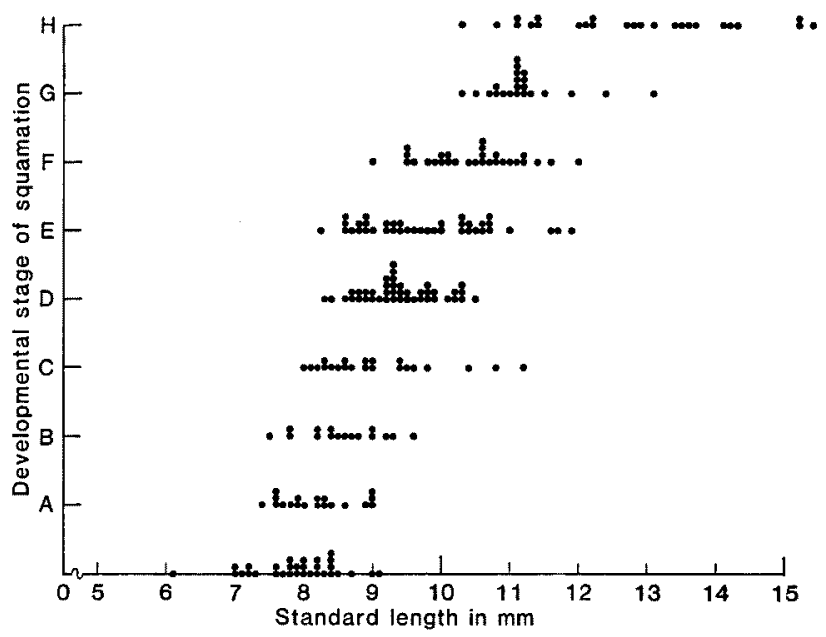

Fig. 8. The relationship between the stages of squamation shown in Fig. 7 and standard length.

high prey density populations as also noted for herring, ${ }^{13)}$ anchovy, ${ }^{20)}$ plaice ${ }^{21)}$ and porgy. ${ }^{22)}$ The majority of survivors remained near the bottom of the rearing tank. Concealment and cannibalism were observed among the bottom dwellers Thus, a sift in swimming mode was believed to be correlated with the transformation from larvae to juveniles.

\section{Larval Distribution and Behavior in the Pond}

During the course of larval development and growth, the most drastic morphological and be- havioral changes occurred when the fish were $7.6 \mathrm{~mm}$ to $8.6 \mathrm{~mm} \mathrm{SL}$ as mentioned previously. Larval fish size during the pelagic life phase and size at which the fish settled to the bottom were investigated in an earthen pond $\left(10,000 \mathrm{~m}^{2}, 70 \mathrm{~cm}\right.$ deep) used to raise the frys for transplantings. Differences in larval behavior between fish raised in the tank and those under natural conditions were compared.

Observation of SCUBA diving was performed to ascertain the minimum size of fish inhabiting the bottom at night (8:00-12:00). Night observa- 


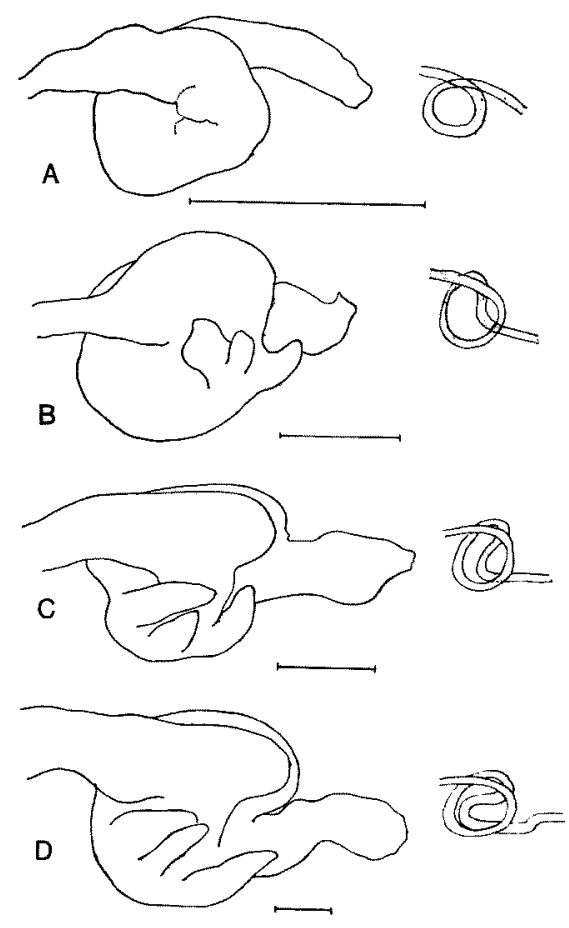

Fig. 9. Schematic illustration showing development of digestive organs. Scales denote $1.0 \mathrm{~mm}$.

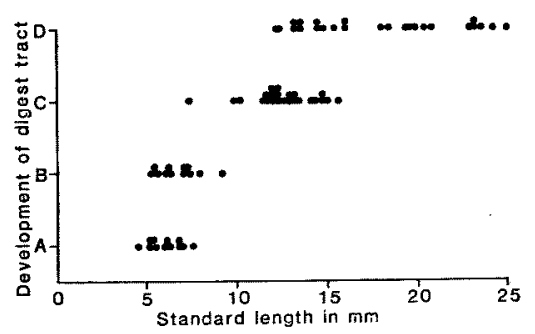

Fig. 10. Relation between developmental stage of digestive organs plotted against standard length. Refer to Fig. 9 for the developmental stage A-D.

tions were made because larvae that rested on the bottom were vulnerable to diver-held hand nets during that time period. Captured specimens were measured immediately by calipers and were then released. The mean size of the bottom residents was $12.0 \mathrm{~mm}$ SL. The smallest fish was found to be $10.5 \mathrm{~mm} \mathrm{SL}$ after 150 diver observations. The larvae that had settled to the bottom had completely formed the two black bands, clearly evident on the side between the dorsal and anal fins (Fig. 5E). Fig. 13 shows the size composition of the larvae, which were aggregated, in

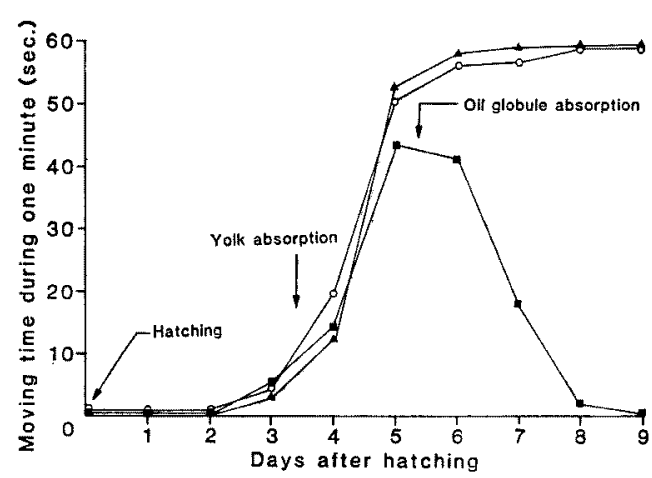

Fig. 11. Increment of moving time during each oneminute observation with larval growth. Closed triangles fed in ambient temperature averaged at $18.4^{\circ} \mathrm{C}$ (range; $15.4^{\circ}-19.8^{\circ} \mathrm{C}$ ); Open circles indicate fed, and closed squares, unfed at a constant temperature of $17.0 \pm 0.5^{\circ} \mathrm{C}$.

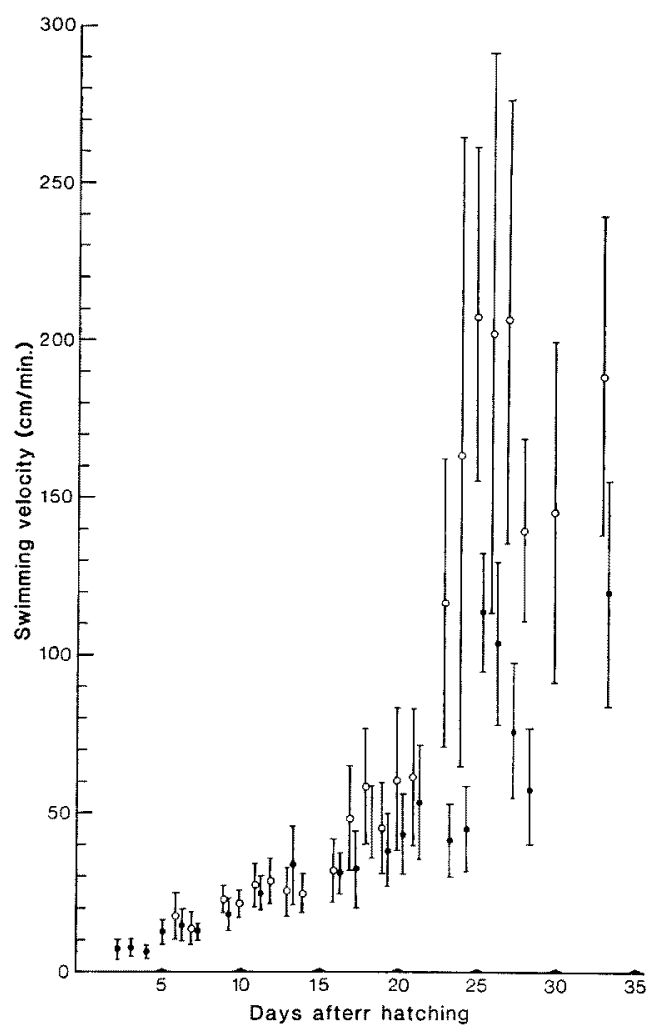

Fig. 12. Increase in swimming speed with growth of larvae before (open circles) and after (closed circles) feeding. ${ }^{17)}$ Each point and vertical lines show the mean of 10 measurements and the standard deviation, respectively. 

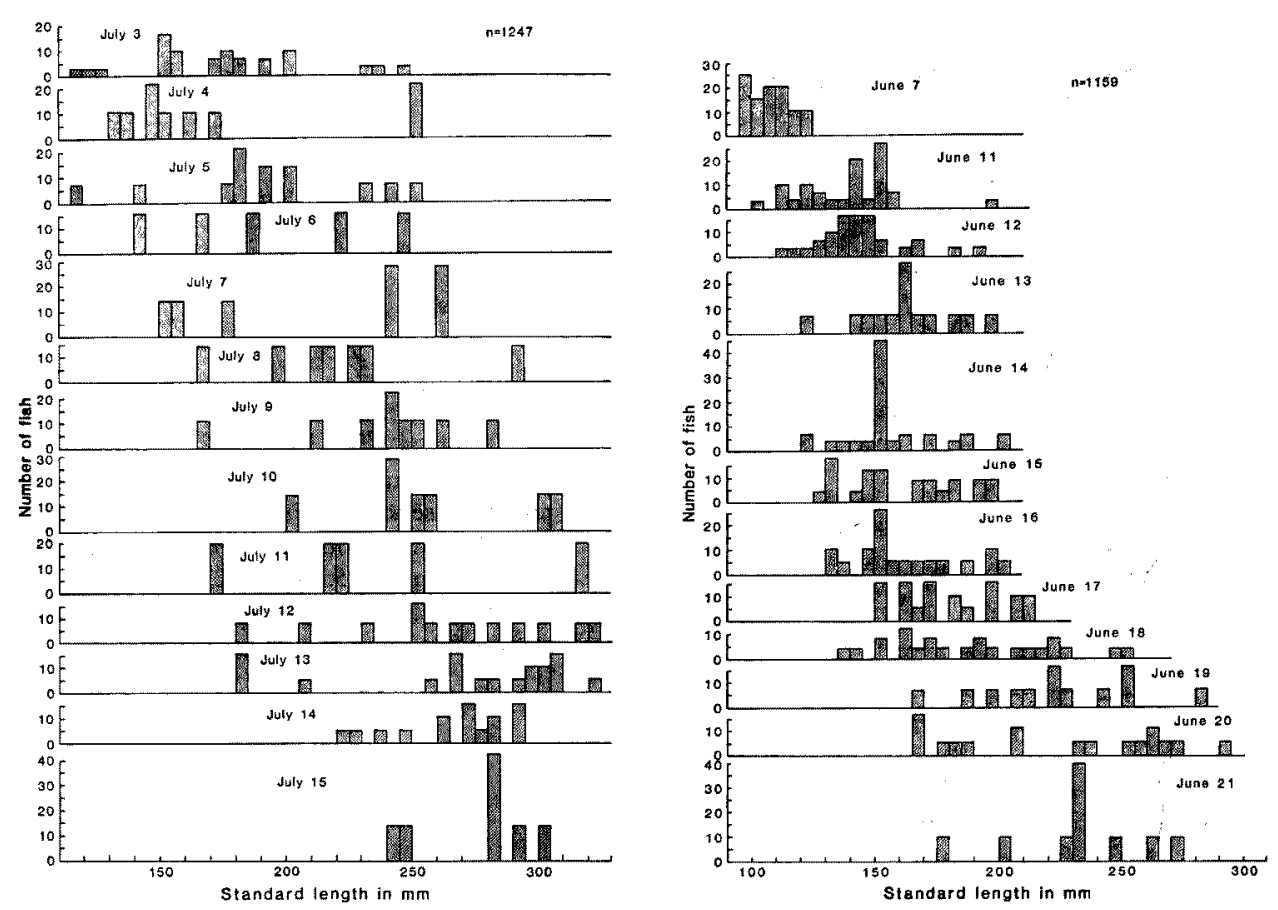

Fig. 13. Size composition of larval fish captured during the night by an attracting light bulb in an earthen pond.

the planktons attracted at night by the electric bulb on the surface. Larval size (length) increased daily. Maximum size for the fish sampled at the water surface was about $32.0 \mathrm{~mm} \mathrm{SL}$, whereas larger specimens were more abundant on the bottom below the attracting bulb. The maximum size of pelagic juveniles attracted to the artificial illumination ranged from 30.0 to $32.0 \mathrm{~mm}$ SL in another earthen pond. These findings suggest that juveniles more than approximately $30.0 \mathrm{~mm}$ in length change completely from a pelagic to a bottom-dwelling life style.

\section{Growth and Allometric Growth}

The increase in length of larvae sampled from $500 \mathrm{l}$ and $1 \mathrm{~m}^{3}$ containers is presented in Fig. 14. Specimens grew slowly during the larval phase, which lasted about 25 days following hatching; thereafter fast growth was attained by juvenile red sea bream.

The larval length, and days after hatching was equated by $Y=2.62 \cdot e^{0.0480 x}$, where $Y=$ total length, and $X=$ days after hatching. The transformation period of $7.6 \mathrm{~mm}$ to $8.6 \mathrm{~mm} \mathrm{SL}$ was correlated with day 25 to 29 . Daily increment was

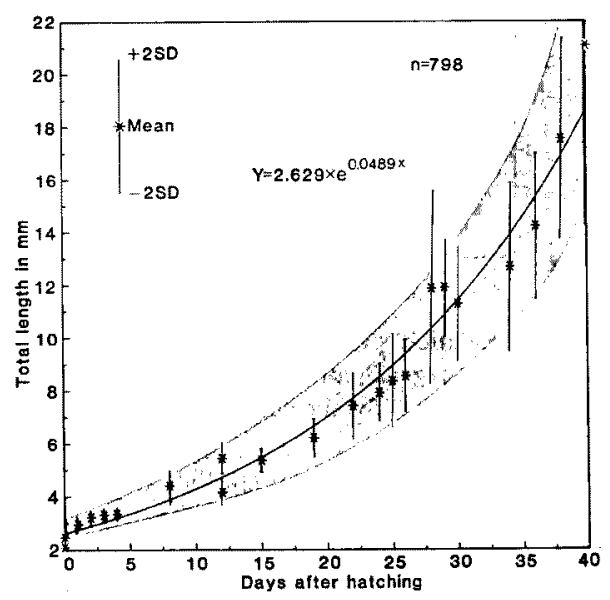

Fig. 14. Growth in length of larval red sea bream reared in $500 \mathrm{l}$ and $1 \mathrm{~m}^{3}$ under laboratory conditions at ambient water temperatures ranging from $17.0^{\circ}$ to $26.0^{\circ} \mathrm{C}^{13)}$ Shaded area was drawn free hand.

presented by $5 \%$ from the equation.

Pertinent to allometric growth, preanal length of newly hatched larvae was $55 \% \mathrm{TL}$ and decreased 


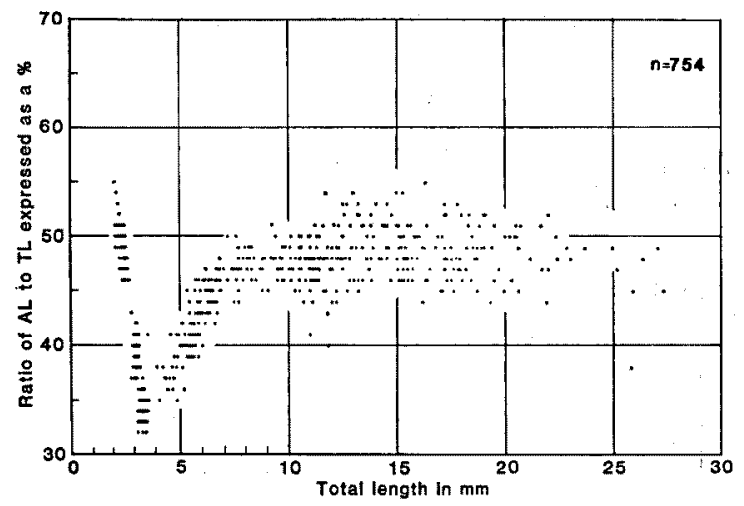

Fig. 15. Proportional measurement of anal length related to total length.

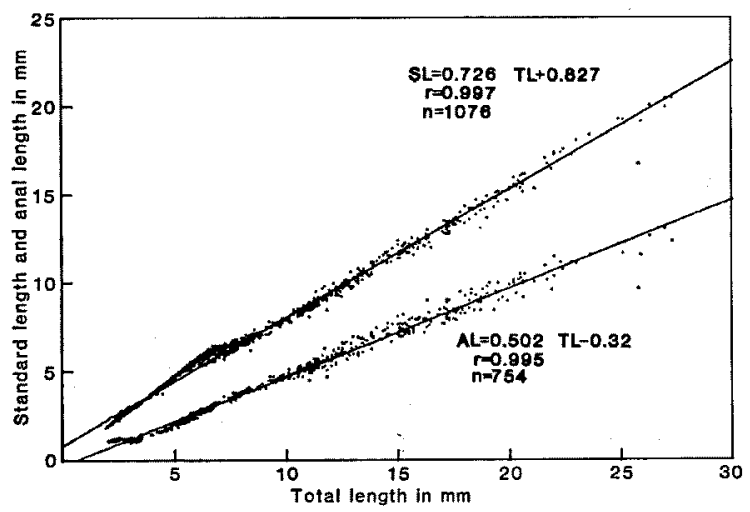

Fig. 16. Standard length and anal length measured from the tip of snout to the anus plotted against total length in larval and juvenile red sea bream.

rapidly to $32 \% \mathrm{SL}$ with the absorption of the yolk sac and oil globule. The ratio again increased to $45 \% \mathrm{TL}$ or $47 \% \mathrm{TL}$ as the larvae fed, then became constant at $47 \%$ to $50 \%$ TL when the fish reached the transitional phase from post-larvae to juvenile stage (Fig. 15).

Other morphometric characters: total length, upper jaw length ${ }^{23)}$ and the body height-notochord length relation ${ }^{8)}$ also revealed constant ratios during the transformation and early juvenile stages. SHIROTA ${ }^{23)}$ discussed the ecological significance of morphometrics as they occurred concurrently with various organs.

Standard length was used to examine the development and growth in relationship to other morphometric characters. Linear regressions between total length, standard length and preanus length are given in Fig. 16 for specimens ranging from $2.2 \mathrm{~mm}$ to $27 \mathrm{~mm}$ TL.

\section{Discussion}

The sequence of the development of external and internal characters, and behavior of red sea bream is summarized in Table 2. The horizontal bars indicate the range in length between the largest specimen with undeveloped features and the smallest with fully developed features. The vertical areas, ranging from 7.6 to $8.6 \mathrm{~mm} \mathrm{SL}$, indicate the transformation phase from the postlarvae to juvenile stage. The development of various organs described herein began during the transitional phase from larvae to juvenile.

Considering the behavioral functional of most external organs, the fins are primitive organs and are related closely with swimming ability. Larvae with primordial fin-fold swam at a rate of $1 \mathrm{SL} /$ s. and were vulnerable to predators such as Sagitta and mullet (unpublished) as described by 
Table 2. The sequence of development of morphological characters in early life stage for red sea bream

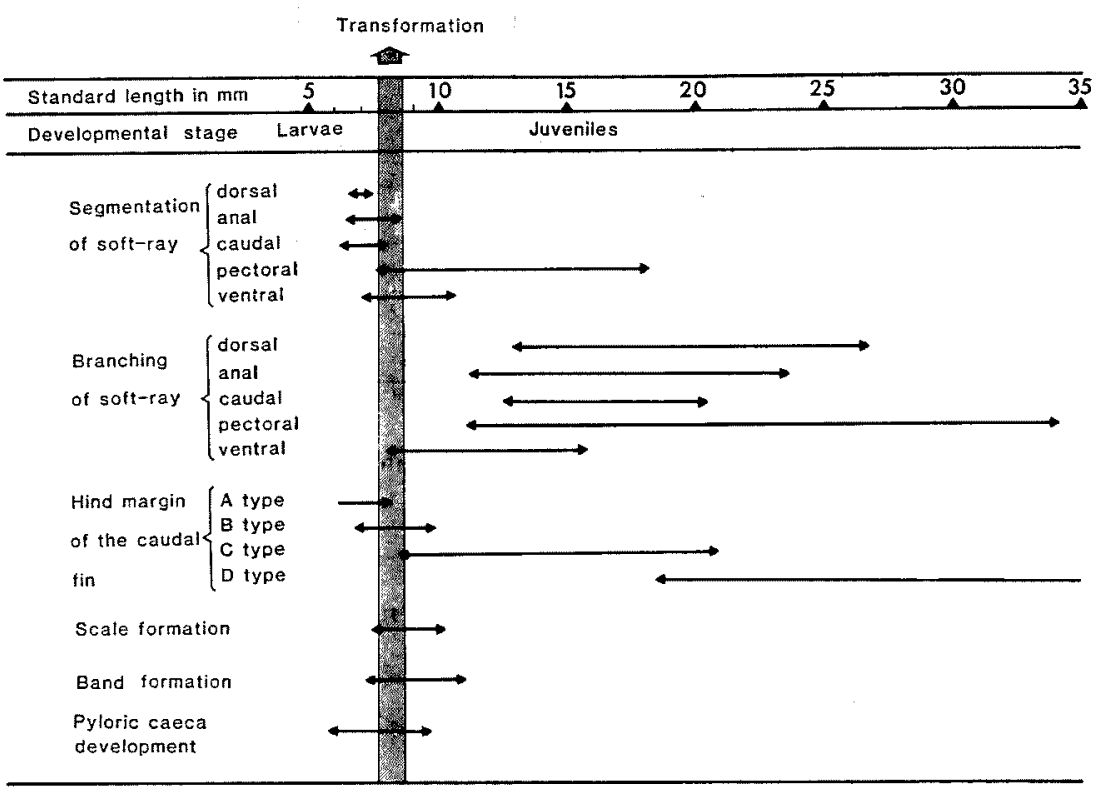

Refer to the Fig. 3 for the hind margin of caudal fin.

Fukuhara. ${ }^{24)}$ However, as they grew, a marked increase in swimming speed was attained as the fin rays developed after metamorphosis (Fig. 12). In addition, the paired fins developed after transformation, thus their new shapes enhanced swimming.

The primary functional role of the bands is generally believed to be concealment, camouflage and intraspecific communication. ${ }^{25-272}$ The band formation occurred in conjunction with morphological and habitational transition for various fish species. ${ }^{28-31)}$ Therefore, the formation of bands is indicative of a change in the life style.

The body surface is protected from various stimuli $^{25,27)}$ by mucous or scales for different species and for different life stages. The juveniles that are fully squamated are assumed to more tolerant of a wider range of environmental conditions than are the larvae lacking scales on the body surface.

Internally, gastric gland was differentiated at 20 days old, followed by the pyloric caeca (Figs. 9, 10) as also demonstrated by TANAKA. ${ }^{\text {B) }}$ According to TANAKA, the differentiation of the gastric gland is strongly related to the transition from larvae to juveniles, which requires more development of the digestive mechanisms as the fish prepare for new foods in a new habitat. The differentiation of the pyloric caeca is also indicative of transforming post-larvae to juveniles.

As the larvae started to prey on ground diets in the rearing tank, a differentiation in the mode of cannibalism and territory was noted when they approached the transitional phase. Furthermore, swimming speed increased remarkably as shown in Fig. 12. The marked increment in swimming ability was presumably caused by the development of the myotomal musculature as well as fin development.

The largest size of pelagic larvae, and the smallest that settled to the bottom, indicating the change in habitats, ranged from about $8.0 \mathrm{~mm}$ to 12.0 mm SL for various field observations. ${ }^{32-34}$ ) In this study the mean size of pelagic juveniles was $12.0 \mathrm{~mm} \mathrm{SL}$, and the smallest size fish settling to the bottom of the earthen pond was $10.5 \mathrm{~mm}$ SL. Consequently, the transformation from the pelagic to the benthic phase occurred during similar periods for both in reared and wild specimens.

During the course of larval development, organogenesis appeared to accompany not only functional capabitilies but also ecological changes. The features of development in external, internal organs and behaviors described herein demonstrate that morphological changes in larval red sea bream followed the functional capabilities, 
and were highly correlated with a transformation in the early life style of the species.

\section{Acknowledgements}

The author express sincere thanks to Professor T. IWAI, Kyoto University, for the suggestion and advice for the manuscript. Thanks also due to Dr. C. S. MaNooch, Southeast Fisheries Center, Beaufort Laboratory for his critical review of the manuscript. I am indebted to Mr. K. NogamI, Mr. T. Fushiml, and Mr. S. Umezawa for their unfailing assistance through the course of this study.

\section{References}

1) Y. Shoujma: in "Studies on the Eggs, Larvae and Juvenile of Japanese Fishes" Series 1, Second Laboratory of Fisheries Biology, Fisheries Department, Faculty of Agriculture, Kyushu Univ., 1958, pp. 71-73.

2) S. Mrto: Japan. J. Ichthyol., 11, 48-52 (1963).

3) O. FUKUHARA: Aquiculture, 17, 71-76 (1969).

4) C. Kтталма: Special Rep. Nagasaki Pref. Insti. of Fish., No. 5, 1-92 (1978).

5) F. Koga: Bull. Fukuoka Pref. Fukuoka Fish. Exp. St. Shouwa 46 Nendo, 217-224 (1973).

6) M. TANAKA: Japan. J. Ichthyol., 18, 164-174 (1971).

7) M. MAtsuoKa: Japan. J. Ichthyol, , 29, 285-294 (1982).

8) H. Kohno, Y. Taki, Y. Ogasawara, Y. Shirojo, M. TAKETOM, and M. INOUE: Japan. J. Ichtyol. 30, 47-60 (1983).

9) M. MATSUOKA and T. IwaI: Bull. Japan. Soc. Sci. Fish., 50, 29-36 (1984).

10) K. YAMASHITA: Japan. J. Ichthyol., 29, 193-202 (1982).

11) K. Yamashita: Japan. J. Ichthyol., 29, 279-284 (1982).

12) C. P. O'Connell: Amer. Zool., 21, 429-446 (1981).
13) O. Fukuhara: Bull. Nansei. Reg. Fish. Res. Lab., No. 16, 85-94 (1984).

14) O. Funuhara: Bull. Nansei. Reg. Fish. Res. Lab., No. 9, 1-11 (1976).

15) O. Fukuhara: Bull. Nansei. Reg. Fish. Res. Lab., No. 11, 1-8 (1978).

16) O. Fukuhara: Bull. Nansei. Reg. Fish. Res. Lab., No. 9, 13-18 (1976).

17) O. Fukuhara and T. Kishida: Bull. Nansei. Reg. Fish. Res. Lab., No. 12, 9-20 (1980).

18) W. A. Gosline: Functional Morphology and Classification of Teleostean Fishes. The University Press of Hawaii, 1973, pp. 22-49.

19) H. Rosenthal and G. Hempel: in "Marine Food Chains" (ed. by J.H. Steele), Univ. Calif. Press, Berkeley, 1970, pp. 344-364.

20) J. R. Hunter and G. L. Thomas: in "The Early Life History of Fish" (ed. by J. H. S. BlaxTER), Springer-Verlag, Berlin Heidelberg, 1974, pp. 559-574.

21) T. WYATT: Marine Biology, 14, 210-216 (1972).

22) O. Funuhara: Bull. Nansei Reg. Fish. Res. Lab., No. 15, 97-101 (1983).

23) A. Shirota: Bull. Japan. Soc. Sci. Fish., 44, 1179-1182 (1978).

24) O. Fukuhara: Bull. Nansei Reg. Fish. Res. Lab., No. 17, 151-153 (1984).

25) K. F. LAGLER, J. E. BARDACH, and R. R. MilleR: Ichthyology: The study of fishes. John Wiley and Sons, New York, 1962, pp. 108-133.

26) H. B. Cort: Adaptive Coloration in Animals. Methven, London, 1940, pp. 49-438.

27) J, R. Norman: A History of Fishes. Ernest Benn Limited, London, 1975, pp. 195-216.

28) A. Zama, M. Asal, and F. Yasuda: Japan. $J$. Ichthyol., 24, 26-34 (1977).

29) K. Fuкusнo: Japan. J. Ichthyol., 22, 23-30 (1975).

30) G. HoshiaI: Japan. J. Ichthyol., 24, 35-42 (1977).

31) S. L. Schroder and T. M. ZARet: Copeia, 1, 43-47 (1979).

32) K. Yamabuki and H. Itano: Fish. Eng., 11, 914 (1975).

33) K. Morr: Bull. Seikai Reg. Fish. Res. Lab., No. $54,59-78(1980)$. 